\title{
Stability and change in kelp forest habitats at San Nicolas Island
}

\author{
Michael C. Kenner ${ }^{1, *}$ And M. Tim Tinker ${ }^{2,3}$ \\ ${ }^{1}$ University of California Santa Cruz, Long Marine Laboratory, 115 McAllister Way, Santa Cruz, CA 95060 \\ ${ }^{2}$ U.S. Geological Survey, Western Ecological Research Center, Long Marine Laboratory, \\ 115 McAllister Way, Santa Cruz, CA 95060 \\ ${ }^{3}$ Present affiliations: University of California Santa Cruz, Long Marine Laboratory, 115 McAllister Way, \\ Santa Cruz, CA 95060; 11 Parklea Dr., Head of St. Margarets Bay, Nova Scotia B3Z 2G6, Canada
}

\begin{abstract}
AвsтRACT.—Kelp forest communities are highly variable over space and time. Despite this complexity it has been suggested that kelp forest communities can be classified into one of 2 states: kelp dominated or sea urchin dominated. It has been further hypothesized that these represent "alternate stable states" because a site can remain in either of these states for decades before some perturbation causes a rapid shift to the other state. Our research group has maintained a subtidal community monitoring program for 38 years at San Nicolas Island consisting of twice-annual scuba-based surveys at 6 sites distributed within 4 regions around the island. Three types of perturbations are thought to be relevant to subtidal community dynamics at San Nicolas: (1) physical disturbances in the form of major storm and El Niño/ Southern Oscillation (ENSO) events; (2) invertebrate diseases, which periodically decimate urchin populations; and (3) the reintroduction and subsequent increase of sea otters (Enhydra lutris nereis). These 3 perturbations differ in spatial and temporal specificity; physical disturbances and disease outbreaks occur periodically and could affect all 4 regions, while sea otter predation has been concentrated primarily at the West End sites over the last 15 years. The different types of perturbations and the duration of the time series at the kelp forests at San Nicolas make the data set ideal for testing the "alternate stable state" hypothesis. We use nonmetric multidimensional scaling (NMDS) to examine spatial and temporal patterns of community similarity at the 4 regions. In particular, we evaluate support for the existence of stable states, which are represented on NMDS plots as distinct spatial clusters. Community dynamics at each site approximated a biased random walk in NMDS space, with one or more basins of attraction and occasional jumps between basins. We found evidence for alternative stable states at some sites, and we show that transitions from one stable state to another may be influenced by interactions between multiple perturbations.
\end{abstract}

RESUMEN.-Las comunidades forestales de algas marinas son muy variables en tiempo y espacio. Sin embargo, pese a tal complejidad, se planteó que las comunidades forestales de algas marinas pueden clasificarse en uno de dos estados: dominadas por algas marinas o dominadas por erizos de mar. También se formuló la hipótesis de que estos representan "estados estables alternos," ya que un sitio puede permanecer en cualquiera de estos estados durante décadas antes de que alguna perturbación provoque un rápido cambio hacia el otro estado. Nuestro grupo de investigación mantuvo, durante 38 años, un programa de monitoreo comunitario submareal en la isla de San Nicolás que consistió en estudios bianuales basados en el buceo, en 6 sitios distribuidos en 4 regiones alrededor de la isla. Tres tipos de alteraciones se consideran de importancia en las dinámicas de la comunidad submareal de San Nicolás: (1) la alteración física, dada en forma de grandes tormentas y de los sucesos ENSO (oscilación meridional de El Niño); (2) las enfermedades de los invertebrados, que diezman, periódicamente, las poblaciones de erizos; y (3) la reintroducción y el posterior aumento de nutrias marinas (Enhydra lutris nereis). Estas 3 alteraciones difieren en cuanto a su especificidad espacial y temporal: la perturbación física y los brotes de enfermedad ocurren periódicamente y pueden afectar a las 4 regiones, mientras que la depredación de la nutria marina se concentró, principalmente, en West End en los últimos 15 años. La presencia de estos tipos de alteraciones y la duración de las series de tiempo hacen de San Nicolás un conjunto de datos ideal para probar la hipótesis del "estado estable alterno." Para examinar los patrones de tiempo y de espacio de similitud comunitaria en las 4 regiones usamos la escala multidimensional no métrica (NMDS, por sus siglas en inglés). Específicamente, evaluamos el respaldo de la existencia de estados estables, representados en gráficos de NMDS como áreas espaciales distintas. Las dinámicas de la comunidad en cada sitio se asemejan a una caminata sesgada azarosa en el espacio de NMDS, con una o más cuencas de atracción y con saltos ocasionales entre las cuencas. Encontramos, en algunos sitios, evidencia de estados estables alternos y mostramos que las transiciones de un estado estable a otro pueden verse influenciadas por interacciones entre múltiples alteraciones.

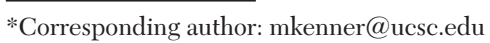


Ecologists have long recognized that species composition and other characteristics in biological communities do not vary randomly. Communities are generally found in one of several "states," and these alternative states may each represent stable points (Sutherland 1974, May 1977). "Community state" is described by one or many variables, often called dynamic state variables, which can include the relative abundances of species or guilds as well as other biotic or abiotic traits such as the amount of unoccupied space or the amount of biogenic habitat (Beisner et al. 2003). Stability is key and is generally taken to mean that the community state exhibits "resilience" (Holling 1973), whereby it will tend to move back toward its original configuration after being perturbed in the same way that a ball sitting within a basin will tend to roll back toward the center of the basin after a small push (Scheffer and Carpenter 2003). The latter metaphor has resulted in the concept of a "basin of attraction" used to describe the range of perturbations (e.g., environmental stressors, additions or removals of species) to which the community is resilient. A community within a basin of attraction will tend to stay there unless exposed to a sufficiently large perturbation, in which case the community may shift to a different (alternative) state (Scheffer et al. 2001). Understanding the factors that cause communities to shift from one stable state to another is important because unexpected shifts in state can have substantial socioeconomic implications, including fisheries collapses, disease outbreaks, or largescale changes in vegetation (Beisner et al. 2003).

One of the ecosystems often highlighted as a textbook example of alternative stable states are the kelp forest systems found on rocky reefs in nearshore coastal areas (Ebeling et al. 1985, Steneck et al. 2002). The concept of alternative stable states in kelp forests is based on the observation that subtidal kelp forest communities appear to most often exist in one of 2 states: an algal-dominated state or a sea urchin-dominated state (Estes and Duggins 1995). It has been suggested that both of these states are relatively stable; a particular community may remain in one state indefinitely until some significant perturbation-an unusually disruptive storm or the invasion of a new predator-drives a shift to the alternate state.
Shifts between stable states tend to be nonlinear and rapid, such that communities rarely occur in "intermediate" phases. Moreover, the details of a phase shift (i.e., the level of the perturbation or the point at which the phase shift occurs) may differ depending on which state the community starts from, a phenomenon known as "hysteresis" (Hughes et al. 2005). The magnitude of this difference has been estimated to be 10 -fold in terms of sea urchin biomass for the transition between a kelp and urchin state, depending on direction (Ling et al. 2015). The above characterization of alternate stable states in kelp forests has been supported by multiple studies (Konar and Estes 2003, Watson and Estes 2011, Steneck et al. 2013, Filbee-Dexter and Scheibling 2014) but has been criticized by some researchers who feel it represents too narrow a view and tends to ignore common but less obvious intermediate phases and questions of scale (Foster and Schiel 1988, 2010). Meta-analysis of kelp forest systems does not suggest a consistent pattern of stable states, but rather suggests that local drivers may be important in determining community state in different systems (Krumhansl et al. 2016).

If we accept that community dynamics in kelp forests may, in some cases, be well described by an alternate stable state paradigm, questions remain about the predictability of phase shifts, how such shifts may differ among sites, and how they are affected by physical or environmental factors. For example, if we subject a sample of kelp forest communities to the same perturbation (e.g., the introduction of a predator that reduces urchin abundance), will all of the communities respond similarly or will the nature of the shift depend on the physical and environmental factors unique to each site? And if a community is perturbed from a kelp-dominated to an urchin-dominated state, but urchins are then removed, will the community return to its original state (in terms of species composition)? If so, this would imply predictability and also suggest that the particular physical or biotic characteristics of the site dictate the equilibrium community state. Alternatively, if a very different community develops, this would suggest a more stochastic process of community assembly following a perturbation.

Subtidal benthic communities around San Nicolas Island (SNI), in the southern California 


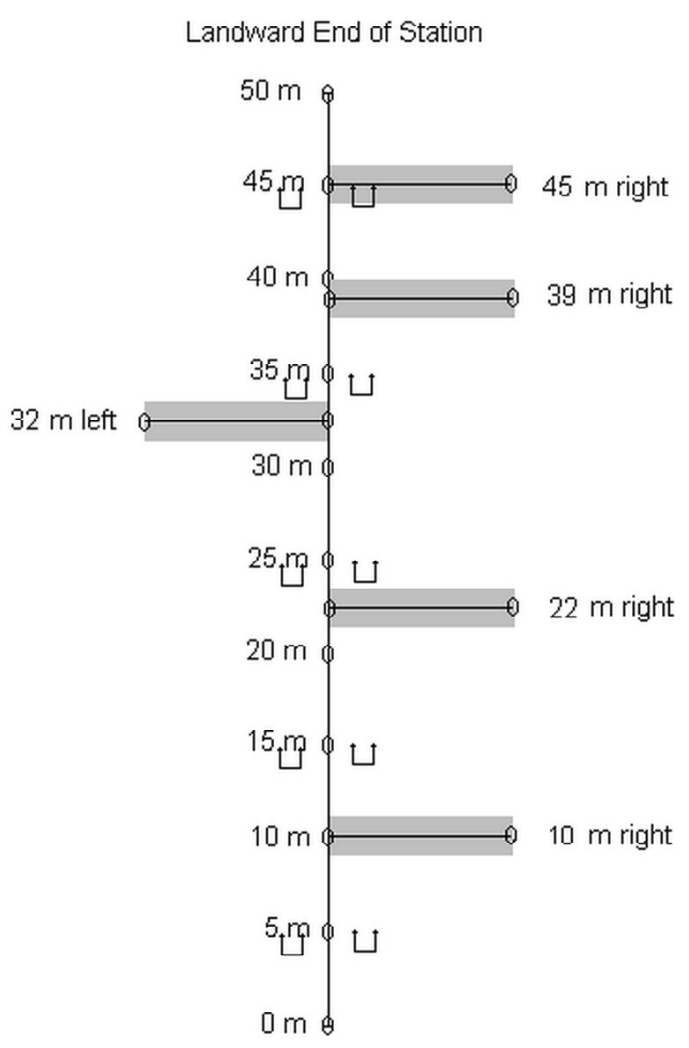

Seaward End of Station

Fig. 1. Schematic of a typical site showing the arrangement of benthic $20-\mathrm{m}^{2}$ density swaths and $1-\mathrm{m}^{2}$ cover quadrats. The main transect is $50 \mathrm{~m}$ long with eyebolts at 5 -m increments. Swaths are $10 \mathrm{~m}$ long by $2 \mathrm{~m}$ wide. Typical swath placement is shown. $\uparrow \uparrow$ symbols represent $1-\mathrm{m}$ point contact quadrats defined by 2 bolts $1 \mathrm{~m}$ off the line.

Bight, provide an ideal opportunity to examine support for stable states in kelp forest systems. Originally established in 1980 to document the impact of a proposed translocation of sea otters to the island, the 6 permanent subtidal sampling sites have generated one of the longest continuous time series on the composition and dynamics of rocky reef benthic communities in the northeastern Pacific. Here we examine community dynamics at 4 sites in kelp forest habitats which have been closely monitored for over 3 decades. The sites, though separated by $<15 \mathrm{~km}$, are exposed to different levels of storm-generated waves and have experienced different intensities of sea urchin grazing and disease. In addition, these sites have been subjected to a temporal and spatial gradient of sea otter foraging as the otter population established there by translocation in the late 1980s has increased at some sites but not others. Three of the sites have undergone deforestation events from which they have recovered to varying degrees. We use multivariate graphical and analytical techniques to evaluate support for alternative stable states and to make inferences about the perturbations that might cause communities to shift between states.

\section{Methods}

\section{Field Methods}

Six permanent, long-term subtidal sites were established around SNI in 1980 (Kenner et al. 2013) and have been sampled twice a year since then. For this analysis, the published data set (extending from 1980 to 2011) was augmented by additional data collected between 2012 and spring 2017. A full explanation of the field methods may be found in Kenner et al. (2013), but to summarize in brief: kelps and a suite of motile molluscan and echinoderm invertebrates were counted on 5 permanent $10 \times 2$-m swaths arranged perpendicular to one side or the other of a 50-m main transect line at each site. In addition to these swath counts, the proportional cover of algae, nonmotile invertebrates, exposed substrate, and a few classes of motile invertebrates were measured using a point contact method (20 points within each of 10 permanent $1-\mathrm{m}^{2}$ quadrats at each site). The cover quadrats were also placed at intervals at one side or the other $1 \mathrm{~m}$ off the main transect line (Fig. 1).

For the purposes of this analysis, the paired sites at West End were combined and the data pooled as one site, as were those at Dutch Harbor. The 2 main 50-m transects defining the West End sites form a continuous 100-m transect whereas those of the 2 proximal Dutch Harbor sites are about $140 \mathrm{~m}$ apart, separated by a sand channel. Pooling the data from these paired sites was considered justified due to the sites' similarity and resulted in a total of 4 different sites (Fig. 2). The depth of the main transects at the sites range from approximately $10 \mathrm{~m}$ to $13 \mathrm{~m}$, with 3 of the sites varying in depth by only about $2 \mathrm{~m}$ throughout the sampled area. At Dutch Harbor, however, high-relief reefs soar as much as $4 \mathrm{~m}$ in abrupt faces and contain abundant cracks and ledges. 


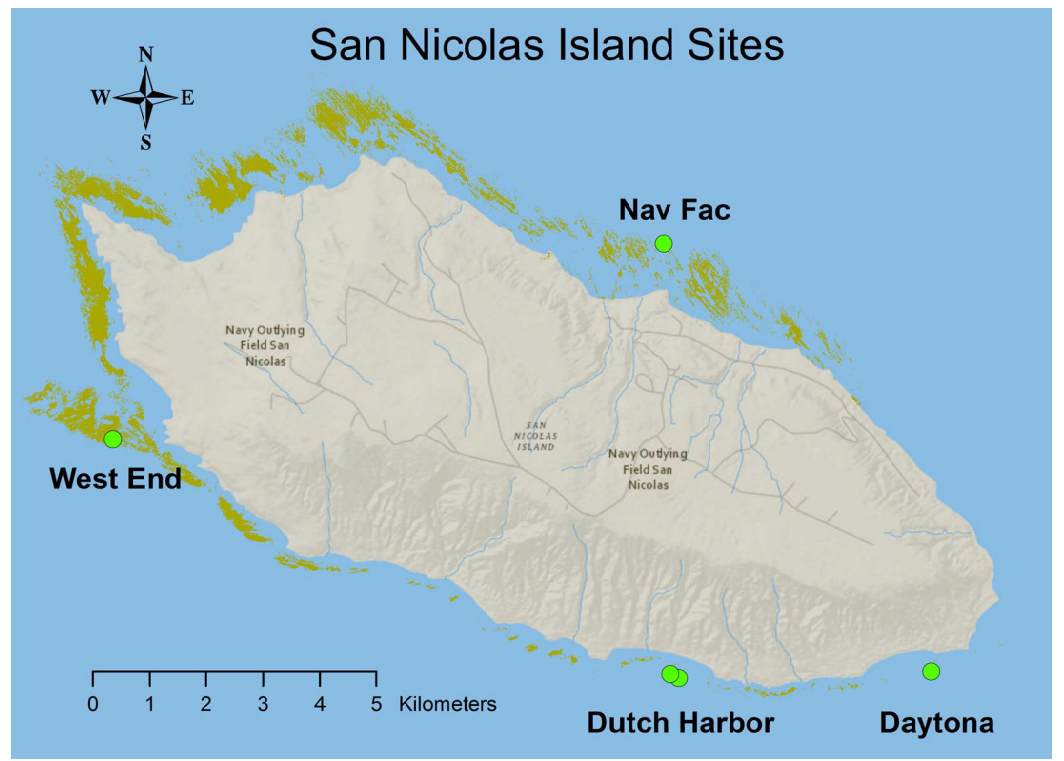

Fig. 2. Location of the 4 sites around San Nicolas Island. West End and Dutch Harbor each have a pair of adjacent sites combined in this analysis. Macrocystis surface canopy is shown (2008).

\section{Analytical Methods}

We conducted a nonmetric multidimensional scaling (NMDS) analysis (Borg and Groenen 2005) of 2 data sets: count data of species on the permanent $20-\mathrm{m}^{2}$ density swaths and proportional cover data from the fixed $1-\mathrm{m}^{2}$ cover quadrats. Two abalone species on swaths-Haliotis rufescens and $H$. corrugata, which were always rare and have been almost entirely absent from all sites for the last 2 decades-were excluded from analysis. This resulted in the following 17 categories of swath-counted species: 1 fucoid alga (Cystoseira osmundacea), 6 kelps (Eisenia arborea, Pterygophora californica, Laminaria spp., young Laminariales, Macrocystis pyrifera $>1 \mathrm{~m}$, and $M$. pyrifera $<1 \mathrm{~m}$ ), 2 gastropods (Megastraea undosa and Megathura crenulata), 1 sea cucumber (Parastichopus parvimensis), 2 sea urchins (Strongylocentrotus franciscanus and S. purpuratus), and 5 sea stars (Pisaster giganteus, Pycnopodia helianthoides, Patiria miniata, Dermasterias imbricata, and Astrometis sertulifera). The mean density of each category was calculated for each site in each sampling period for which data were available (Fig. 3A).

Species and groups appearing in the cover data were assigned to the following 8 categories: bare rock, sand, brown algae (not including kelp), sea cucumber, encrusting algae, erect coralline algae, fleshy red algae, and nonmotile invertebrates. Species already represented in the count data (e.g., C. osmundacea) or which represented rare categories (e.g., green algae) were not included in the analysis of cover data. The sea cucumbers in the cover data are small but sometimes very numerous species primarily of the genera Cucumeria and Pachythyone. As with the count data, a mean value was calculated for each category, site, and sampling period.

Both data types were $\log (\mathrm{x}+1)$ transformed prior to analysis in order to normalize the data. Additionally, in order to combine the 2 data types into a single NMDS analysis, we rescaled the cover data; specifically, we multiplied log-transformed cover data by a factor of 1.75 , a value selected to equalize the mean relative abundances across all categories for both sampling methods (rescaling was preferable to variable normalization, as the latter method tends to reduce the influence of dominant species and exaggerate the influence of rare species).

Multidimensional scaling analyses were performed using PRIMER v6 ${ }^{\circledR}$. After transformation, the 4 sites were analyzed together and then separately using the combined count and 
A

\begin{tabular}{|c|c|c|c|c|c|c|c|c|c|c|c|c|c|c|c|}
\hline $\begin{array}{c}\text { Sample } \\
\text { Period }\end{array}$ & $\begin{array}{c}\text { Season } \\
\text { Year }\end{array}$ & $\begin{array}{c}\text { Sample } \\
\text { Period } \\
\text { cont. }\end{array}$ & $\begin{array}{c}\text { Season } \\
\text { Year } \\
\text { cont. }\end{array}$ & $\begin{array}{c}\text { Sample } \\
\text { Period } \\
\text { cont. }\end{array}$ & $\begin{array}{c}\text { Season } \\
\text { Year } \\
\text { cont. }\end{array}$ & $\begin{array}{c}\text { Sample } \\
\text { Period } \\
\text { cont. }\end{array}$ & $\begin{array}{c}\text { Season } \\
\text { Year } \\
\text { cont. }\end{array}$ & $\begin{array}{c}\text { Sample } \\
\text { Period } \\
\text { cont. }\end{array}$ & $\begin{array}{c}\text { Season } \\
\text { Year } \\
\text { cont. }\end{array}$ & $\begin{array}{c}\text { Sample } \\
\text { Period } \\
\text { cont. }\end{array}$ & $\begin{array}{c}\text { Season } \\
\text { Year } \\
\text { cont. }\end{array}$ & $\begin{array}{c}\text { Sample } \\
\text { Period } \\
\text { cont. }\end{array}$ & $\begin{array}{c}\text { Season } \\
\text { Year } \\
\text { cont. }\end{array}$ & $\begin{array}{c}\text { Sample } \\
\text { Period } \\
\text { cont. }\end{array}$ & $\begin{array}{c}\text { Season } \\
\text { Year } \\
\text { cont. }\end{array}$ \\
\hline & I F 1980 & 10 & S 1985 & 20 & S 1990 & 30 & S 1995 & \multicolumn{2}{|c|}{40 S 2000} & \multicolumn{2}{|c|}{50 S 2005} & 60 & S 2010 & \multicolumn{2}{|c|}{70 S 2015} \\
\hline & 2 S 1981 & 11 & F 1985 & 21 & F 1990 & 31 & F 1995 & \multicolumn{2}{|c|}{$41 F 2000$} & 51 & F 2005 & 61 & F 2010 & 71 & F 2015 \\
\hline & F 1981 & 12 & S 1986 & 22 & S 1991 & 32 & S 1996 & 42 & S 2001 & 52 & S 2006 & 62 & S 2011 & 72 & S 2016 \\
\hline & S 1982 & 13 & F 1986 & 23 & F 1991 & 33 & F 1996 & 43 & $F 2001$ & 53 & F 2006 & 63 & F 2011 & 73 & F 2016 \\
\hline & F 1982 & 14 & S 1987 & 24 & S 1992 & 34 & S 1997 & 44 & S 2002 & 54 & S 2007 & 64 & S 2012 & 74 & S 2017 \\
\hline & S 1983 & 15 & F 1987 & 25 & F 1992 & 35 & F 1997 & 45 & $F 2002$ & 55 & F 2007 & 65 & F 2012 & & \\
\hline & F 1983 & 16 & S 1988 & 26 & S 1993 & 36 & S 1998 & 46 & S 2003 & 56 & S 2008 & 66 & S 2013 & & \\
\hline & S S 1984 & 17 & F 1988 & 27 & F 1993 & 37 & F 1998 & 47 & F 2003 & 57 & F 2008 & 67 & F 2013 & & \\
\hline & F 1984 & 18 & S 1989 & 28 & S 1994 & 38 & S 1999 & 48 & S 2004 & 58 & S 2009 & 68 & S 2014 & & \\
\hline (conti & hued $\rightarrow>$ ) & 19 & F 1989 & 29 & F 1994 & 39 & F 1999 & 49 & F 2004 & 59 & F 2009 & 69 & F 2014 & & \\
\hline
\end{tabular}

B

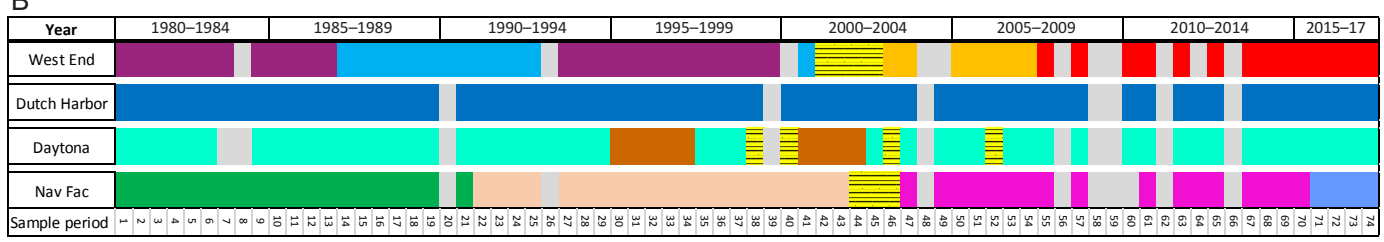

Fig. 3. A, Key for linking sample period numbers (as referenced in the NMDS plots) to the season ( $\mathrm{F}=$ fall, $\mathrm{S}=$ spring) and year of each sampling event. The color of each sample period corresponds to point colors in the NMDS plots. B, Timeline of state changes at the 4 sites. Colors are a progression from one NMDS grouping to another, as defined by $75 \%$ similarity. Similar colors between sites do not imply similar states. Light gray denotes missing data, and yellow hatched areas indicate periods during which the community appeared to be in a transitional state.

cover data. A Bray-Curtis similarity index was computed for each site, and NMDS plots were generated from the resulting similarity matrices. We used analysis of similarity (ANOSIM) to test whether variation in community states differed significantly among sites (Clarke 1993). Graphical analyses of NMDS plots were then used to evaluate support for the existence of multiple stable states at each site. Our a priori expectations were as follows: Support for the existence of a stable state at a given site would be assumed if the time series of community state over time (represented by ordered points on the NMDS ordination) was tightly clustered, suggesting a "central point of attraction" for community composition. Similarly, support for alternative stable states would be implied if there were 2 (or more) distinct clusters with occasional transitions of the community from one cluster to another, representing phase shifts. Alternatively, a lack of any distinct clusters (e.g., a diffuse cloud of points on the NMDS ordination suggestive of an unbiased random walk) would provide evidence against the existence of alternative stable states. We identified clusters using a simple agglomerative, hierarchical clustering of the resemblance matrix with an a priori 75\% similarity threshold (PRIMER v6).
Sea otter abundance was measured and analyzed separately. Sea otters around SNI were surveyed at least twice annually by shore-based observers, as described elsewhere (Tinker and Hatfield 2016). All data were digitized into a geo-spatial database, and the relative densities of sea otters in the region of each subtidal site were calculated as 3-year running averages of the maximum annual counts within a circle with a radius of $4 \mathrm{~km}$ centered on each site. This spatial domain was selected to measure the abundance of otters likely to influence each site via predation, based on previous analyses of the mean home range size of sea otters at SNI (Tinker et al. 2008). The resulting time series of sea otter abundance at each site was combined with NMDS plots of community state dynamics. Specifically, each point on the NMDS plot (representing the community state at site $i$ at time $t$ ) was scaled to the relative abundance of sea otters to graphically examine the role that sea otter recovery may have played in driving phase shifts in community state.

\section{RESUlTs}

There was substantial variation in community composition at SNI, both between and within sites, over the course of data collection. 


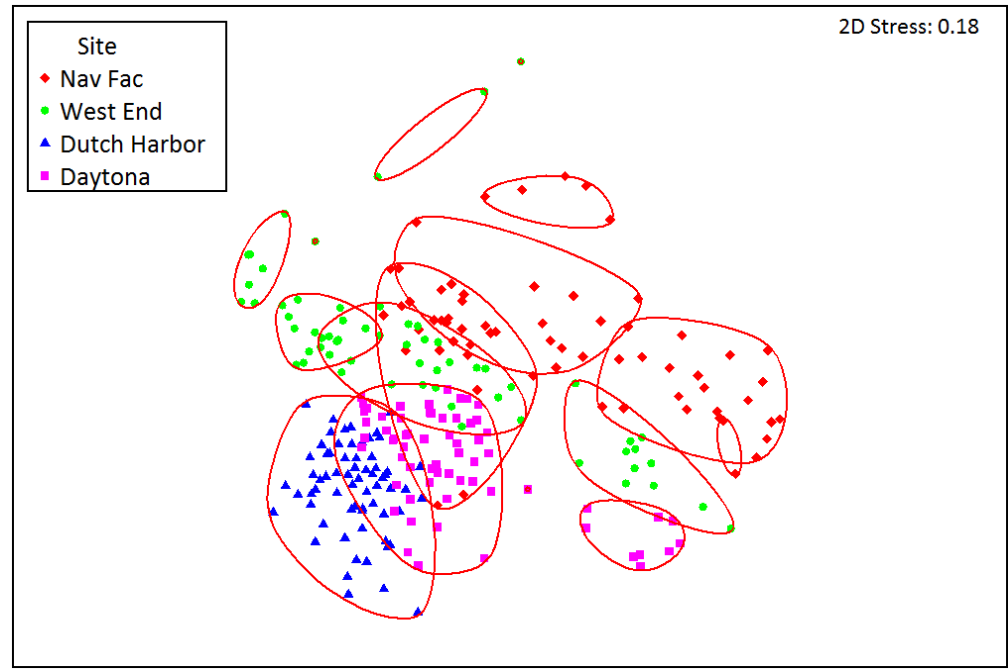

Fig. 4. The 4 sites projected onto a common pair of NMDS axes. Similarity clusters at the $75 \%$ level are depicted.

An NMDS ordination of all survey data plotted on common 2 dimensional axes (Fig. 4) shows a significant degree of separation by site (ANOSIM $\mathrm{P}<0.01$ ). Three of the sites showed a multimodal pattern, characterized by 2 (or more) distinct clusters, while Dutch Harbor remained entirely within a $75 \%$ similarity grouping over the full 38 -year period. The West End site showed the greatest range of variation between clusters.

Each of the 4 sites has a unique character and history. West End, the most exposed site, has also been the most dynamic (Fig. 5A). It became dominated by the purple urchin, $S$. purpuratus, in the late 1980s (period 14). The urchin population crashed briefly in 1993 (period 27) then soon rebounded before almost disappearing in 2001 (period 42). Following this most recent urchin population crash, various algal regimes dominated, with high densities of $M$. pyrifera eventually giving way to high-density understory kelps and increased cover of lower-lying fleshy red algae. The opposite extreme is Dutch Harbor (Fig. 5B), which has maintained moderate levels of urchins and kelps with mixed algal and invertebrate cover. This site, which is relatively protected except from southern swells, has never transitioned to one dominated by sea urchins. The remaining 2 sites are intermediate in dynamics. Daytona (Fig. 5C), with an exposure similar to that of Dutch Harbor, originally supported a high-density under- story of Cystoseira and Laminaria but became dominated by S. purpuratus in the mid-1990s (period 30). The urchins underwent brief declines in 1998 (period 35) and 2003 (period 45) before rebounding. The site remains a mix of urchin-dominated and kelp-dominated areas. Nav Fac (Fig. 5D), which-like West End-is exposed to the northwest, had a species composition similar to Daytona until it also was dominated by increasing numbers of S. purpuratus in 1991 (period 22). Here, too, urchins declined briefly in 2003 (period 46) and again dropped to low levels in 2015. It is likely that all of the rapid urchin declines described above were initiated by disease. Although diseased individuals were not observed, this assumption is based on swift reductions of high-density urchin populations where evidence of other causes was lacking (Behrens and Lafferty 2004, Lafferty 2004).

Figure 6 shows NMDS plots of community state dynamics for each site, with groupings of points (clusters) identified at the $75 \%$ similarity level. Though some of the periods are clearly transitional (e.g., periods $42-45$ at West End), most of the clusters at each site appear to represent basins of attraction (sensu Scheffer and Carpenter 2003) insomuch as community state tended to vary within a relatively small area of total NMDS space over periods of years to decades. Transitions between clusters were generally rapid, and communities at some sites have transitioned between clusters more 

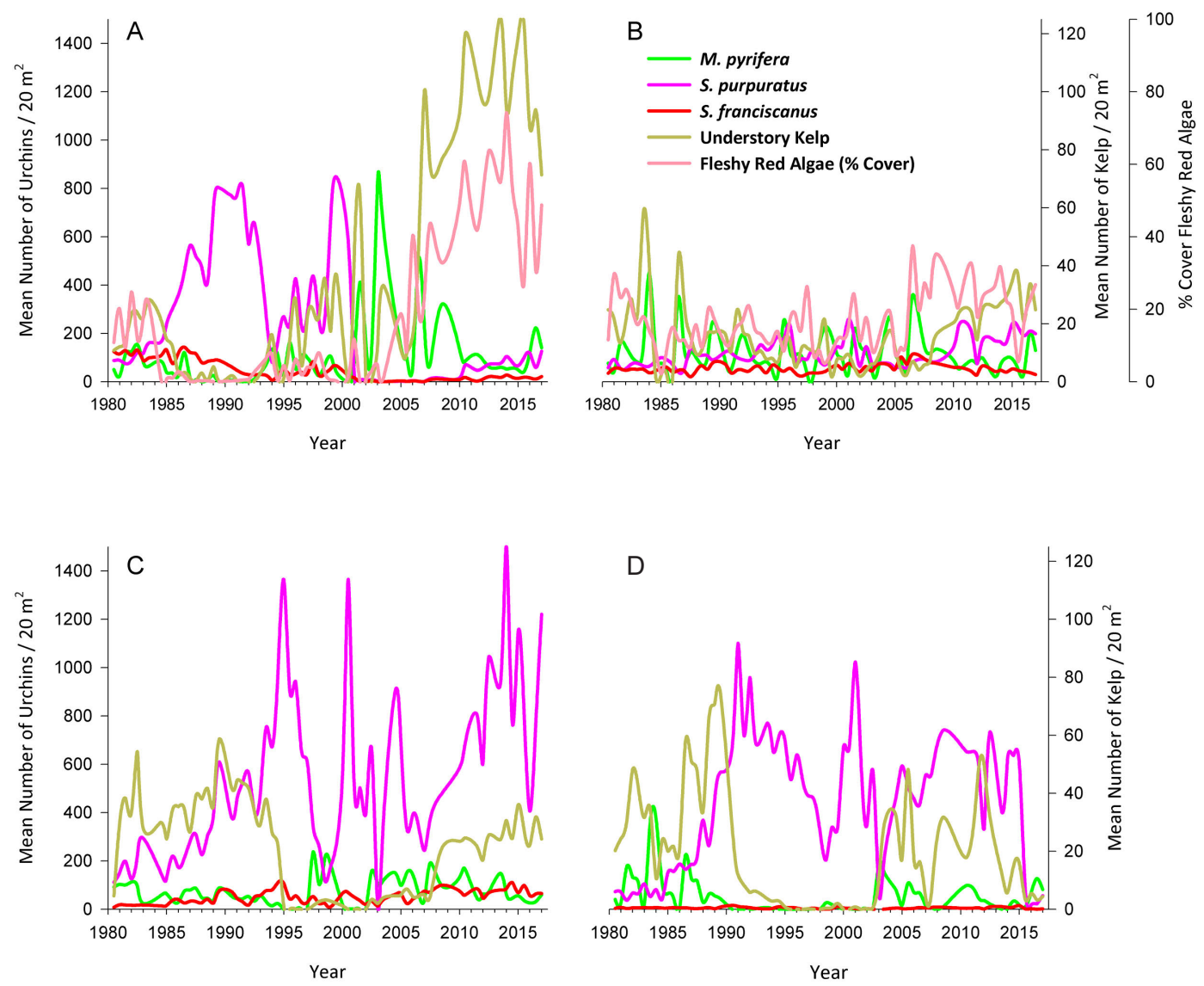

Fig. 5. Temporal changes in major ecosystem components at the 4 sites: A, West End; B, Dutch Harbor; C, Daytona; D, Nav Fac.

than once. The West End site for example repeatedly passed in and out of an urchindominated cluster (lower left of Fig. 6A), a state where purple urchins and encrusting coralline algae predominated and fleshy algae were sparse. A similar pattern was seen at Daytona (Fig. 6C, urchin-dominated cluster at lower left) and Nav Fac (Fig. 6D, urchindominated cluster at upper right). Figure 3B shows a timeline of these transitions for all 4 sites. Both West End and Nav Fac underwent a state shift in the early 2000 s as purple urchin numbers declined sharply at both sites; otherwise there is little sign of synchronicity between the sites. Most states were maintained from 5 years to over 10 years.

The sea otter population at SNI, initialized by the translocation of animals from the central California coast in the late 1980s, has not expanded uniformly around the island. Until
1995 the population numbered at or below a dozen animals but has now increased to approximately 100 (Tinker and Hatfield 2016), and most of the animals reside off the west end of the island for most of the year. Figure 7 shows the NMDS ordinations at each site, with symbol-size corresponding to the number of otters within $4 \mathrm{~km}$ of each site over time. At the West End site (Fig. 7A), the site with the greatest otter abundance, an uptick in sea otters in the early 2000s was associated with a transitional shift (periods 41-45) followed by a convergence on a previously unobserved cluster characterized by dense M. pyrifera (periods 46-52), then a shift to another new cluster characterized by dense understory kelps and fleshy red algae (periods 53-71). These latter 2 "otter-associated" basins of attraction correspond to the 2 farthest-left clusters on the common ordination of all sites (Fig. 4). 


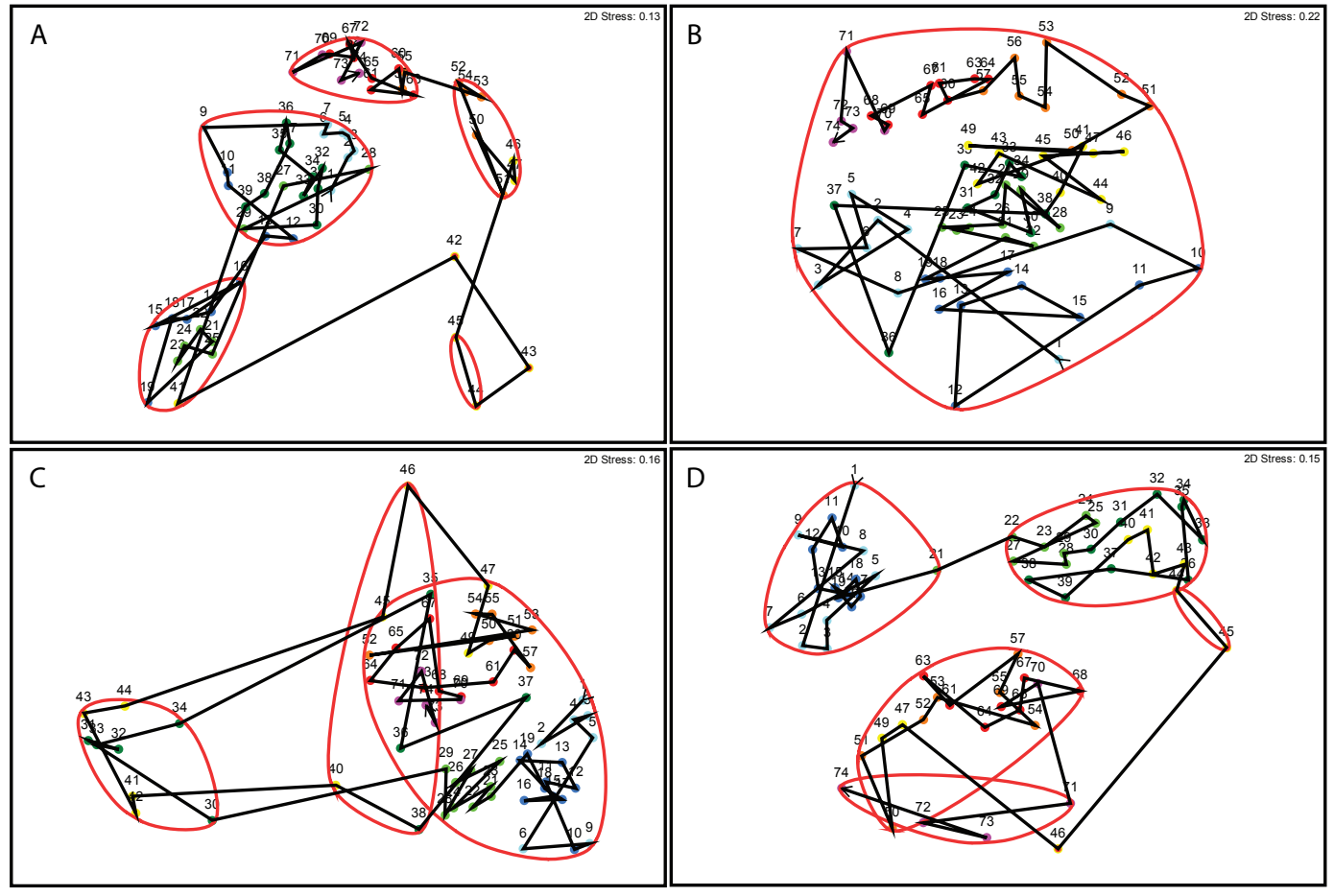

Fig. 6. NMDS 2D plots: A, West End; B, Dutch Harbor; C, Daytona; D, Nav Fac. Numbers represent sampling periods from 1 (fall 1980) to 74 (spring 2017). Symbols are colored by 5 -year increments, and lines connect adjacent sampling periods. Similarity groupings at the $75 \%$ level are shown.

\section{Discussion}

Our analysis lends support for the existence of stable states at all 4 sites. At all sites the community state was persistent over time, represented by tightly clustered points on NMDS ordinations. Because communities persisted within these clusters for years to decades and showed a tendency to return to a cluster centroid following small perturbations, it seems reasonable to characterize these states as basins of attraction for community composition (Scheffer and Carpenter 2003). Indeed, the dynamics of community state in NMDS space resembled the biased random walk of an animal within its home range, where stochastic movements within a cluster are biased toward a central point of attraction. Three of the sites had more than one cluster, implying multiple stable states, and there were occasional and sudden transitions of the community between clusters.

Dutch Harbor has occupied the same state over the entire 38 years of our study, exhibiting no apparent phase shifts. Daytona shows
2 distinct clusters, shifting repeatedly between urchin- and kelp-dominated states. Nav Fac displays 4 distinct clusters, and although it only resided in each state once during our study, it remained in the first 3 for about a decade each before shifting to another. The site has most recently entered a fourth state, during the last 4 periods, following a sharp reduction in sea urchin numbers. Finally, West End displays the most complex pattern of community dynamics, with 4 distinct clusters. As with the Daytona site, the community at the West End site underwent multiple phase shifts between 2 distinct states, one urchin dominated and one kelp dominated; however, after sea urchin numbers fell precipitously in period 42 and sea otter abundance increased, the community transitioned to 2 previously unobserved states.

The complex dynamics at the West End site speak to the question of whether a kelp forest which becomes urchin dominated will return to a similar community composition after the urchins are removed. In the case of the West End after the 2001 urchin population 


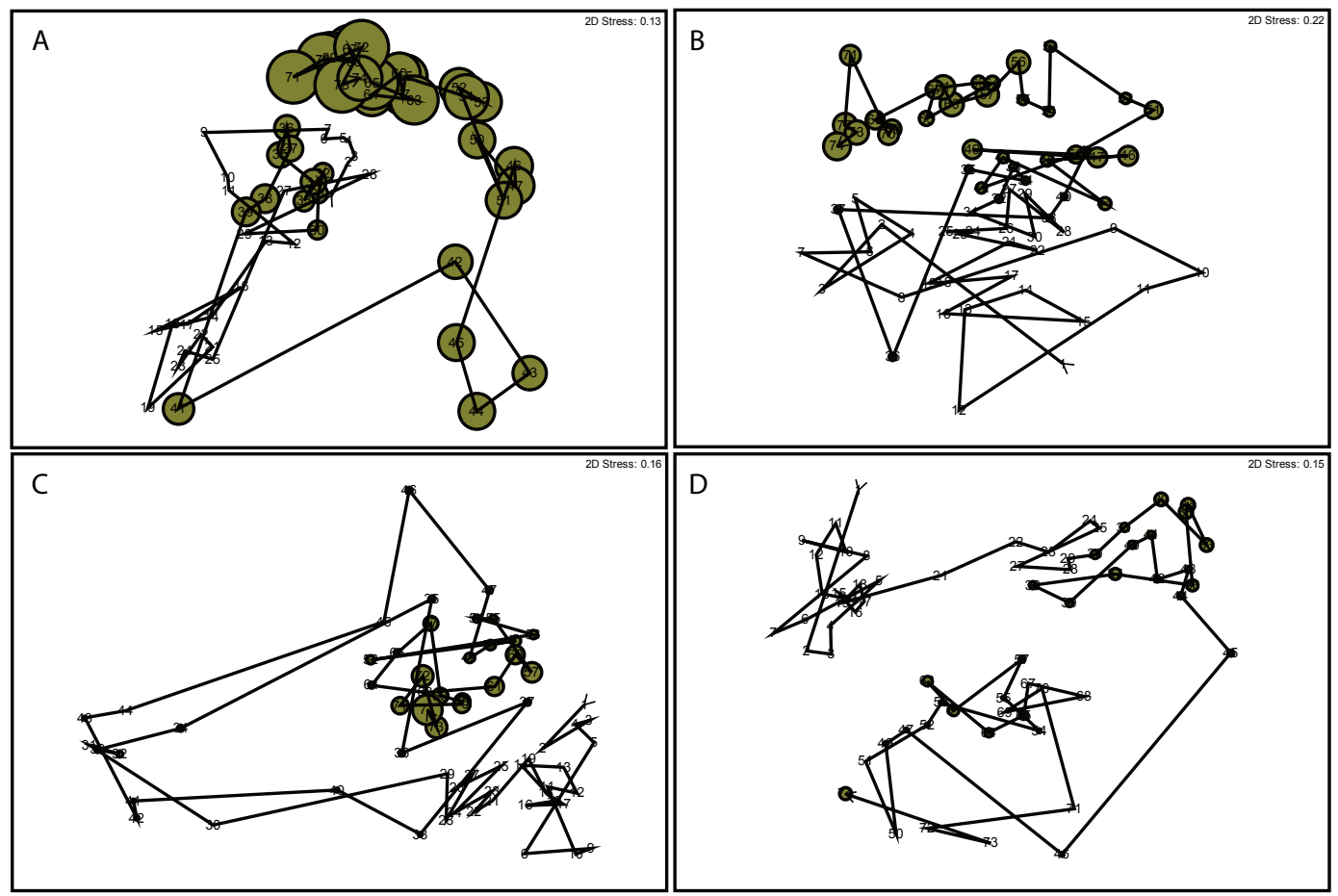

Fig. 7. NMDS 2D plots: A, West End; B, Dutch Harbor; C, Daytona; D, Nav Fac. Diameters of circles over NMDS nodes are scaled to represent the numbers of sea otters within $4 \mathrm{~km}$ of each site. The largest circle on periods 72 and 73 at West End represents 52.7 otters compared to 3.3 otters for the largest concentration at Nav Fac.

crash, that did not happen. Instead the site transitioned to new stable states and is currently much more dominated by fleshy red algae and understory kelp species than at any other time in our series of data.

Over the course of this study, the perturbations causing shifts between alternative states was not always clearly identified, although in some cases inferences can be made. Precipitous declines in sea urchin density are often assumed to be the result of unobserved sea urchin disease outbreaks (Feehan and Scheibling 2014). Increasing sea urchin numbers may result from recruitment pulses or immigration from adjacent areas, and the resulting increase in urchin grazing can result in kelp deforestation. Alternatively, rapid loss of kelp biomass due to extreme storm events may cause a change of state (Harrold and Reed 1985). An entirely different scenario may result if sea urchin densities are depressed for longer periods, as was the case after 2001 at West End. In this case M. pyrifera declined, possibly due to a storm event, apparently allowing a new state to emerge in which storm-resistant understory kelps and red algae dominated. The observed transitions may have been facilitated by the deterrent effect of sea otters on the local sea urchin population.

Sea otters are often cited as being responsible for changes in stable states due to their efficient elimination of exposed sea urchins (Estes and Duggins 1995). In the case of the West End kelp forest, they were likely not the primary cause of the shift that occurred there in period 42 . Sea otters are size-selective foragers. Much of the urchin population there just prior to that point consisted of very small purple urchins resulting from a recent recruitment. The otters were unlikely to concentrate on them, nor on starved sea urchins living in a barren area when larger healthy urchins were to be found in nearby kelp areas. It is therefore more likely that the near extinction of sea urchins observed at the site was the result of disease. There is, however, evidence from observations of tagged sea otters (Tinker et al. 2008) and from sea urchin size data (Kenner 2017) that sea otters foraged extensively on sea urchins at West End after 2001. It is 
therefore likely that sea otters are at least partially responsible for urchin numbers remaining low there for the last decade and thus acted to facilitate the more recent state changes.

Other sea urchin predators have been proposed as important to community structure in the kelp forest habitats of southern California (Hamilton and Caselle 2015). Three of these-the spiny lobster Panulirus interruptus (Tegner and Levin 1983), the sea star Pycnopodia helianthoides (Duggins 1983), and the labrid Semicossyphus pulcher (Cowen 1983) all occur at SNI. No effects from these species on state changes were detected in this study. We lack abundance data for $P$. interruptus at our long-term sites, but the spiny lobster is rarely seen at any of them. Pycnopodia helianthoides is one of the suite of species counted in permanent transects on our sites. They were present in fairly low numbers between 1991 and 2013, but changes in their abundance showed no relationship to the patterns detected here. The sheephead, $S$. pulcher, is counted in visual fish transects as part of our regular sampling protocol (Kenner et al. 2013). We again saw no relationship between changes in their abundance and changes between states at the sites. S. pulcher is most common at Dutch Harbor, however, and it is possible that sheephead predation on urchins is one of several factors that have helped maintain the long-term stability of this site (Hamilton and Caselle 2015). In fact, considering the urchin biomass reduction required to effect a change from an urchin-dominated state (Ling et al. 2015), it is likely that these 3 predators are much better at maintaining stability than initiating a shift between states.

There are several factors which may explain the resilience of the Dutch Harbor community. Bottom relief is higher at this site, and that in itself may partially explain why the densities of $S$. pulcher and other fish species are consistently higher there. The site also has a higher cover of filter feeders and a generally more diverse assemblage of species, all of which may lead to a more stable system.

Although it is beyond the scope of this paper to do this kind of analysis on data from other areas, similar data collected at San Miguel, Santa Rosa, Santa Cruz, Anacapa, and Santa Barbara Islands between 1983 and 2011 (Kushner et al. 2013) indicate that most sites made similar changes between kelpdominated and urchin-dominated states. There seems to be little synchrony between those changes and the ones we report here for SNI, although S. purpuratus densities at several sites at Santa Rosa and Santa Cruz increased dramatically in 1985 and 1986, suggesting a regional sea urchin recruitment event.

What emerges from our analysis is a more complex and nuanced view of the kelp forest stable state paradigm. Our study findings lend support to the view that kelp forest community structure may persist in a fairly stable state for years or decades but that under perturbation the community may shift to another stable state. Our results also demonstrate that more than 2 stable states may be common. Finally, we suggest that the interactive effects of multiple perturbations (including urchin disease, storms, and sea otter predation) may be responsible for shifts between stable states.

\section{ACKNOWLEDGMENTS}

We thank James Estes for his foresight in establishing this project and for his insights into community ecology at San Nicolas. Chris Harrold and Dan Reed were instrumental in installing sites and early sampling efforts. Scores of divers have helped collect these data over the decades; their contributions are gratefully acknowledged here. Sampling has been funded primarily by the U.S. Geological Survey and earlier by other divisions of the Department of the Interior. Since fall 2014 the project has been funded by NAVFAC Southwest of the U.S. Navy. The manuscript has been improved following a critical review by Glenn VanBlaricom and 2 anonymous reviewers.

\section{Literature Cited}

Behrens, M.D., and K.D. Lafferty. 2004. Effects of marine reserves and urchin disease on southern Californian rocky reef communities. Marine Ecology Progress Series 279:129-139.

Beisner, B.E., D.T. Haydon, and K. Cuddington. 2003. Alternative stable states in ecology. Frontiers in Ecology and the Environment 1:376-382.

Borg, I., AND P.J. Groenen. 2005. Modern multidimensional scaling: theory and applications. Springer Science \& Business Media.

Clarke, K.R. 1993. Non-parametric multivariate analyses of changes in community structure. Australian Journal of Ecology 18:117-143. 
Cowen, R.K. 1983. The effect of sheephead (Semicossyphus pulcher) predation on Red Sea urchin (Strongylocentrotus franciscanus) populations: an experimental analysis. Oecologia 58:249-255.

DugGINS, D.O. 1983. Starfish predation and the creation of mosaic patterns in a kelp-dominated community. Ecology 64:1610-1619.

Ebeling, A., D. Laur, and R. Rowley. 1985. Severe storm disturbances and reversal of community structure in a southern California kelp forest. Marine Biology 84:287-294.

Estes, J.A., AND D.O. DugGins. 1995. Sea otters and kelp forests in Alaska: generality and variation in a community ecological paradigm. Ecological Monographs 65:75-100.

Feehan, C.J., AND R.E. Scheibling. 2014. Effects of sea urchin disease on coastal marine ecosystems. Marine Biology 161:1467-1485.

Filbee-Dexter, K., And R.E. Scheibling. 2014. Sea urchin barrens as alternative stable states of collapsed kelp ecosystems. Marine Ecology Progress Series 495:1-25.

Foster, M., AND D. Schiel. 1988. Kelp communities and sea otters: keystone species or just another brick in the wall? Pages 92-115 in A. Estes James and G.R. Vanblaricom, editors, The community ecology of sea otters. Springer, Berlin, Germany.

Foster, M.S., AND D.R. SChiEL. 2010. Loss of predators and the collapse of southern California kelp forests (?): alternatives, explanations and generalizations. Journal of Experimental Marine Biology and Ecology 393:59-70.

Hamilton, S.L., and J.E. Caselle. 2015. Exploitation and recovery of a sea urchin predator has implications for the resilience of southern California kelp forests. Proceedings of the Royal Society B: Biological Sciences 282:20141817.

Harrold, C., AND D.C. ReED. 1985. Food availability, sea urchin grazing, and kelp forest community structure. Ecology 66:1160-1169.

HoLLing, C.S. 1973. Resilience and stability of ecological systems. Annual review of ecology and systematics $4: 1-23$.

Hughes, T.P., D.R. Bellwood, C. Folke, R.S. Steneck, AND J. WILSON. 2005. New paradigms for supporting the resilience of marine ecosystems. Trends in Ecology and Evolution 20:380-386.

Kenner, M.C. 2017. San Nicolas Island kelp forest monitoring-second annual report-fiscal year 2016. University of California Santa Cruz, Santa Cruz, CA.

Kenner, M.C., J.A. Estes, M.T. Tinker, J.L. Bodkin, R.K. Cowen, C. Harrold, B.B. Hatfield, M. NovaK, A. RassweILeR, AND D.C. REeD. 2013. A multi-decade time series of kelp forest community structure at San Nicolas Island, California. Ecological Archives E094:244

Konar, B., AND J.A. Estes. 2003. The stability of boundary regions between kelp beds and deforested areas. Ecology 84:174-185.

Krumhansl, K.A., D.K. Окamoto, A. Rassweiler, M. Novak, J.J. Bolton, K.C. Cavanaugh, S.D. Connell,
C.R. Johnson, B. Konar, S.D. Ling, et aL. 2016. Global patterns of kelp forest change over the past half-century. Proceedings of the National Academy of Sciences USA 113:13785-13790.

Kushner, D.J., A. Rassweiler, J.P. McLaughlin, and K.D. LAFFERTy. 2013. A multi-decade time series of kelp forest community structure at the California Channel Islands. Ecology 94:2655.

LAFFERTY, K.D. 2004. Fishing for lobsters indirectly increases epidemics in sea urchins. Ecological Applications 14:1566-1573.

Ling, S.D., R.E. Scheibling, A. Rassweiler, C.R. JohnSON, N. Shears, S.D. CONNEll, A.K. Salomon, K.M. Norderhaug, A. Pérez-Matus, J.C. Hernández, ET AL. 2015. Global regime shift dynamics of catastrophic sea urchin overgrazing. Philosophical Transactions of the Royal Society B: Biological Sciences 370:20130269.

MaY, R.M. 1977. Thresholds and breakpoints in ecosystems with a multiplicity of stable states. Nature 269: $471-477$.

Scheffer, M., S. Carpenter, J.A. Foley, C. Folke, and B. WALKER. 2001. Catastrophic shifts in ecosystems. Nature 413:591.

Scheffer, M., AND S.R. Carpenter. 2003. Catastrophic regime shifts in ecosystems: linking theory to observation. Trends in Ecology and Evolution 18:648-656.

Steneck, R.S., M.H. Graham, B.J. Bourque, D. Corbett, J.M. Erlandson, J.A. Estes, and M.J. Tegner. 2002. Kelp forest ecosystems: biodiversity, stability, resilience and future. Environmental Conservation 29:436-459.

Steneck, R.S., A. Leland, D.C. McNaught, and J. VAVRINEC. 2013. Ecosystem flips, locks, and feedbacks: the lasting effects of fisheries on Maine's kelp forest ecosystem. Bulletin of Marine Science 89: $31-55$.

SutherLand, J.P. 1974. Multiple stable points in natural communities. American Naturalist 108:859-873.

Tegner, M.J., AND L.A. Levin. 1983. Spiny lobsters and sea urchins: analysis of a predator-prey interaction. Journal of Experimental Marine Biology and Ecology 73:125-150.

Tinker, M.T., G. Bentall, and J.A. Estes. 2008. Food limitation leads to behavioral diversification and dietary specialization in sea otters. Proceedings of the National Academy of Sciences of the United States of America 105:560-565.

Tinker, M.T., And B.B. Hatfield. 2016. California sea otter (Enhydra lutris nereis) census results, spring 2016. Report 1018, Reston, VA.

Watson, J., AND J.A. EsTES. 2011. Stability, resilience, and phase shifts in rocky subtidal communities along the west coast of Vancouver Island, Canada. Ecological Monographs 81:215-239.

Received 1 March 2017

Revised 18 October 2017

Accepted 23 October 2017

Published online 16 March 2018 